\title{
Multiple Retroperitoneal Paragangliomas: An Uncommon Entity
}

\author{
${ }^{1}$ Ashu Singh, ${ }^{2}$ Deep Shikha, ${ }^{3}$ Shipra Agarwal, ${ }^{4}$ Nita Khurana, ${ }^{5}$ Shyam Lata Jain, ${ }^{6}$ NS Hadke
}

\section{ABSTRACT}

Introduction: Paragangliomas are neuroendocrine tumors and occur commonly in head and neck region and less frequently in the retroperitoneum. Multifocal paragangliomas are even rarer and highly suggestive of familial disease. To the best of our search, there are only two case reports of multiple retroperitoneal paragangliomas with no known familial association. This is the third report of this kind in the English literature.

Case report: A young adult with no significant past or family history presented with abdominal pain and anorexia. Abdominal examination revealed a soft nontender mass in the right hypochondrium. Contrast-enhanced computed tomography showed multiple retroperitoneal mass lesions. A clinicoradiological diagnosis of multicentric Castleman's disease/Lymphoma was made. Guided fine needle aspiration of the mass was suggestive of a neuroendocrine neoplasm. Tru-cut biopsy showed features of paraganglioma. Following this, the masses were excised and the diagnosis of paraganglioma was confirmed.

Conclusion: Multicentric retroperitoneal paragangliomas without any familial association are very rare with only two case reports in the English literature. Lack of symptoms makes the diagnosis difficult and also makes our case unique. Biopsy from paragangliomas and surgical intervention are known to cause life-threatening complications, such as profuse bleeding and abrupt changes in blood pressure. Hence, paragangliomas should be considered as a possibility, even if a remote one, in case of multicentric retroperitoneal tumors. This case also highlights the importance of cytology in the early diagnosis of retroperitoneal masses.

Keywords: Multiple, Paragangliomas, Retroperitoneal.

How to cite this article: Singh A, Shikha D, Agarwal S, Khurana N, Jain SL, Hadke NS. Multiple Retroperitoneal Paragangliomas: An Uncommon Entity. World J Endoc Surg 2017;9(1):20-23.

\footnotetext{
${ }^{1,3}$ Assistant Professor, ${ }^{2}$ Senior Resident, ${ }^{4-6}$ Director Professor

${ }^{1}$ Department of Pathology, Aarupadai Veedu Medical College Puducherry, India

${ }^{2}$ Department of General Surgery, All India Institute of Medical Sciences, Rishikesh, Uttrakhand, India

${ }^{3}$ Department of Pathology, All India Institute of Medical Sciences New Delhi, India

${ }^{4,5}$ Department of Pathology, Maulana Azad Medical College New Delhi, India

${ }^{6}$ Department of Surgery, Maulana Azad Medical College, New Delhi, India
}

Corresponding Author: Ashu Singh, Assistant Professor Department of Pathology, Aarupadai Veedu Medical College, Puducherry, India, Phone: +918220269769, e-mail: dr.ashusingh@gmail.com
Source of support: Nil

Conflict of interest: None

\section{INTRODUCTION}

Paragangliomas are rare neuroendocrine neoplasms derived from neuroectodermal cells of the autonomous nervous system. ${ }^{1}$ Also christened as extra-adrenal pheochromocytoma, they may occur anywhere from the skull base to the pelvic floor along the distribution of the paraganglia. Paragangliomas when retroperitoneal may pose diagnostic difficulty clinicoradiologically, especially when not associated with symptoms due to hormonal imbalance. Rarely, they may be multicentric, thus adding to the diagnostic dilemma. Two texts have offered information about multiple retroperitoneal paragangliomas in the English literature. ${ }^{2,3}$ We present one such case with an emphasis to consider it as a differential diagnosis of multiple retroperitoneal tumors.

\section{CASE REPORT}

A 26-year-old male presented with pain in periumbilical and right lumbar regions since 2 years, along with recent onset anorexia, and weight loss. There was no significant family or past history. Physical examination revealed a soft, firm, well-defined, bosselated, and nontender $5 \times 4 \mathrm{~cm}$ mass in the right hypochondrium. Contrast-enhanced computed tomography (CECT) abdomen showed multiple well-defined smoothly marginated soft tissue mass lesions in retroperitoneum with near homogenous enhancement and encasing peritoneal vessels. Clinicoradiological diagnosis of multicentric Castleman's disease/ lymphoma was made.

Ultrasonography guided fine needle aspiration cytology using a 23G needle was done. Giemsa stained smears showed highly cellular smears. The tumor cells were predominantly singly dispersed with focal acinar pattern. They were round to oval with centric to eccentric nuclei, scant to moderate focally vacuolated cytoplasm, stippled nuclear chromatin, and 1-2 small inconspicuous nucleoli. Few cells showed red granules in the cytoplasm. There was focal abrupt nuclear pleomorphism with occasional giant nuclei, however no mitosis/necrosis was seen Figure 1. Possibility of a neuroendocrine tumor was suggested.

Tru-cut biopsy was done and three liner tru-cut cores measuring $1 \times 0.2 \times 0.2 \mathrm{~cm}, 0.5 \times 0.2 \times 0.2 \mathrm{cmand} 0.2 \times 0.1 \times 0.1 \mathrm{~cm}$ 
were received. On microscopy showed a highly vascular tumor comprised of polygonal cells with moderate amount of finely vacuolated eosinophilic cytoplasm having round to oval nuclei, fine nuclear chromatin, and small conspicuous nucleoli. The cells were immunopositive for chromogranin, neuron specific enolase, and synaptophysin. Focally, S-100 highlighted the sustentacular cells (Figs 2A to D). Based on these features, diagnosis of paraganglioma was made. Urine metanephrines and vanillylmandelic acid done subsequently were, however, negative. In view of the discrepancy, the patient was subjected to excision of the three masses (Fig 1A). Adrenal glands could be identified separately. On gross pathological evaluation, the tumors measured $7 \times 5 \times 3 \mathrm{~cm}, 6 \times 6 \times 3 \mathrm{~cm}$ and $6 \times 5 \times 3 \mathrm{~cm}$ respectively. They were encapsulated; cut surface being grey brown. Histopathological examination of all confirmed the diagnosis of multiple retroperitoneal paraganglioma.

After 18 months of the excision, the patient remains disease-free.

\section{DISCUSSION}

Paragangliomas are neuroendocrine neoplasms and arise from paraganglia. The latter are widely dispersed collections of specialized neural crest cells that lie adjacent to the sympathetic ganglia and plexuses throughout the body. Tumors that arise from chromaffin cells of the adrenal medulla are called pheochromocytomas, whereas those that occur at extra-adrenal sites are referred to as paragangliomas. ${ }^{4,5}$ Men are affected more frequently than women. ${ }^{6,7}$ They are often sporadic and unifocal but multicentric ones can develop as a part of hereditary tumor syndromes chiefly von Hippel-Lindau disease and multiple endocrine neoplasia (MEN) 2A and 2B, the familial Paraganglioma (PGL) syndromes and, more rarely, neurofibromatosis type I, MEN1, and the tuberous sclerosis complex. ${ }^{8}$
The association of nonfamilial paraganglioma, gastrointestinal stromal tumor, and pulmonary chondroma (Carney triad) has been described in rare patients. ${ }^{9}$

In familial paraganglioma syndrome, there is germline mutation of SDHD (PGL1), SDHB (PGL4), SDHAF2 (PGL2), and rarely SDHC (PGL3). The PGL1 is the most frequent, followed by PGL4, PGL2, and PGL3 are rare. ${ }^{10}$

Presence of multicentric tumors is highly indicative of familial disease especially in children. ${ }^{11,12}$

However, multicentric retroperitoneal paragangliomas with no known family history are extremely rare. To the best of our knowledge, there are only two such case reports. ${ }^{2,3}$ While one of these was diagnosed preoperatively following an episode of hypertension during tumor manipulation, ${ }^{2}$ the other was symptomatic right from the beginning. ${ }^{3}$ The current case presented with symptoms due to the mass effects of the multifocal tumors in the retroperitoneum. Considering the multifocality, possibilities of lymphoma/Castleman's disease were considered. But surprisingly, FNA showed features suggestive of a neuroendocrine neoplasm, which prompted the surgeons to be careful during surgical intervention. Histopathology was diagnostic of multifocal paragangliomas.

Paragangliomas can be functional or nonfunctional. If functional, it synthesizes and secretes catecholamines. This may aid in the diagnosis by evaluating the patient's urine for the catecholamines. Nevertheless, the case under discussion was a nonfunctional one.

Most of the paragangliomas are benign but about $12 \%$ are malignant. ${ }^{11}$ No definite histological or immunohistochemical parameter can predict malignant behavior including extreme atypia, capsular or vascular invasion or areas simulating pediatric neuroblastoma. ${ }^{13}$ Metastasis to a site where paraganglia are not normally present, e.g., lymphnodes/liver/lungs/ bone is the only accepted criterion of malignancy. ${ }^{13,14}$
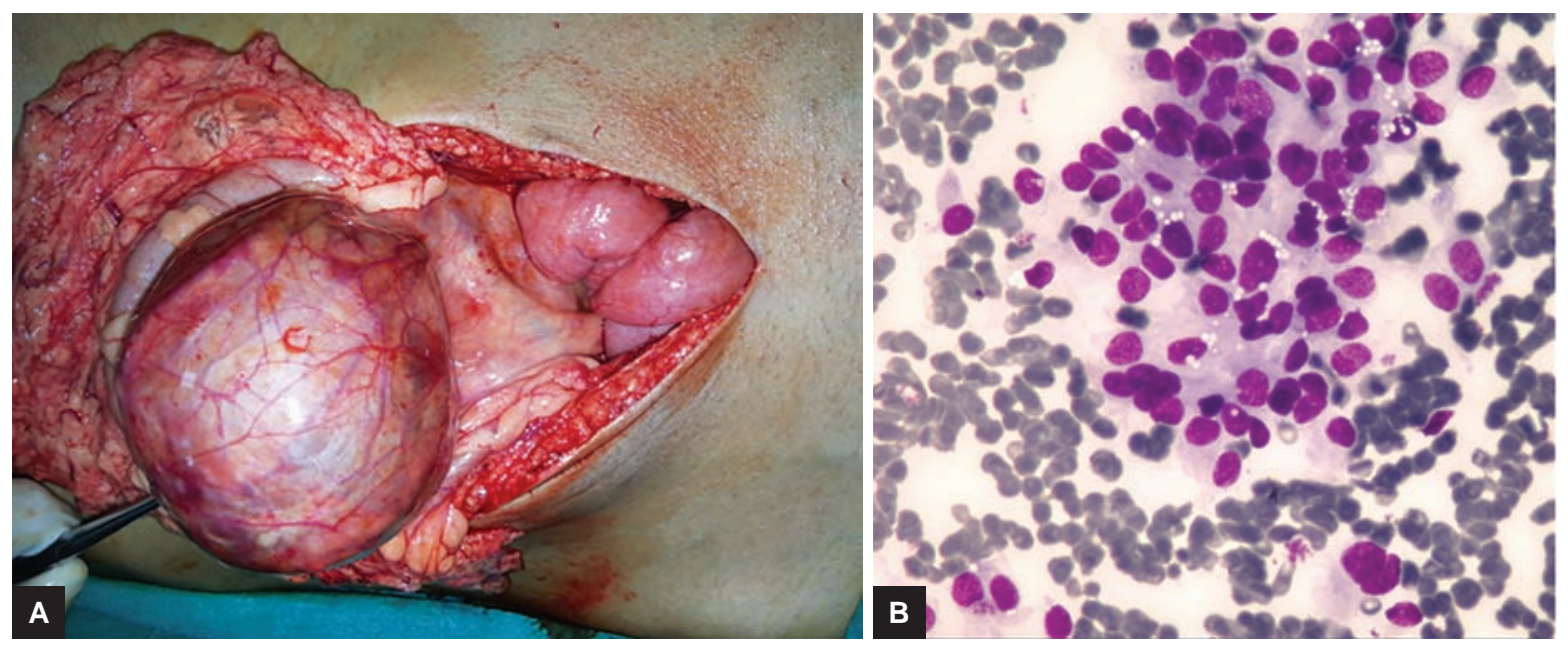

Figs $1 A$ and B: (A) Preoperative picture and (B) cytology smear showing cells in acinar arrangement with occasional bizarre nuclei 

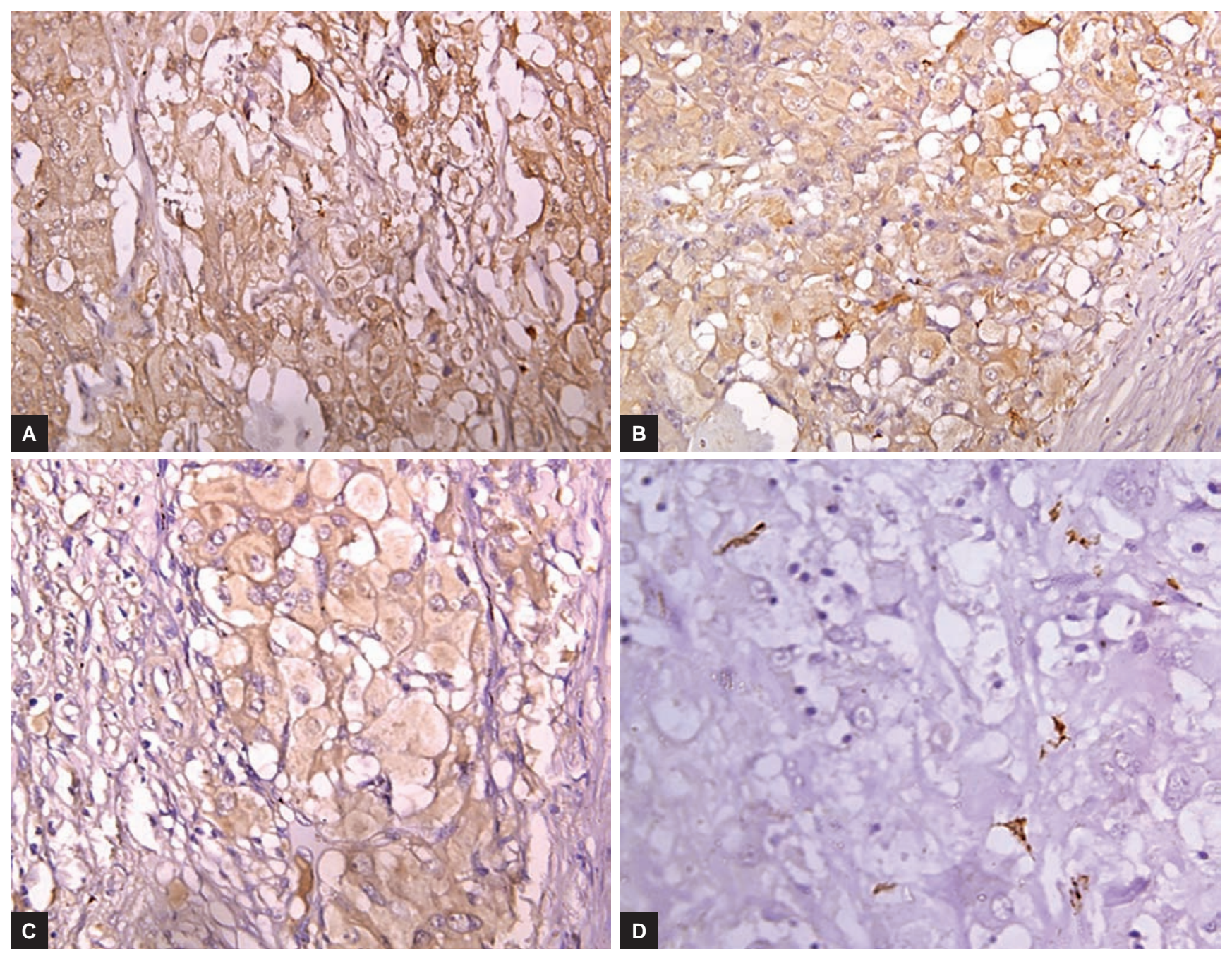

Figs 2A to D: (A to C) Tumor cells positive for chromogranin, synaptophysin, and neuron specific enolase; and (D) sustentacular cells positive for S-100

Making an accurate preoperative clinical diagnosis of paraganglioma is essential, but it is quite difficult when there are no overt symptoms of excess catecholamine release. There are no imaging features specific for paragangliomas. Various radiological imaging modalities, such as CECT, magnetic resonance imaging, and functional testing using nuclear scintigraphy with ${ }^{123}$ I-labeled metaiodobenzylguanidine may be useful for diagnosing and locating multiple tumors. Nevertheless, pathological evaluation is mandatory for a definitive diagnosis.

\section{CONCLUSION}

Extra-adrenal multiple retroperitoneal paragangliomas are rare tumors causing considerable difficulty in clinical diagnosis and treatment. Since paragangliomas can cause significant intraoperative hemodynamic side effects, a high index of suspicion even in atypical clinical settings and preoperative cytological diagnosis may help in avoiding serious complications.

\section{REFERENCES}

1. Kunitz A, Pahl S, Podrabsky P, Wardelmann E and Sturm I. Large paraganglioma of the abdominal cavity: a case report and review of the literature. Onkologie 2010;33:377-380.

2. Guo Q, Li B, Guan J, Yang H, Wu Y. Intraoperative diagnosis of functional retroperitoneal multiple paraganglioma: a case report. Oncol lett 2012 Oct;4(4):829-831.

3. Rai S, Subas K, Kini J, Bhat N, Rao S. Multiple retroperitoneal paraganglioma. Indian J Surg 2013 Jun;75(Suppl 1):125-27.

4. Antonello M, Piazza M, Menegolo M, Opocher G, Deriu GP, Grego F. Role of the genetic study in the management of carotid body tumor in paraganglioma syndrome. Eur J Vasc Endovasc Surg 2008 Nov;36(5):517-19.

5. Yeo H, Roman S. Pheochromocytoma and functional paraganglioma. Curr Opin Oncol 2005 Jan,17(1):13-18.

6. Mikhail RA, Moore JB, Reed DN Jr, Abbott AR. Malignant retroperitoneal paragangliomas. J Surg Oncol 1986 May;32(1): 32-36.

7. Enzinger, FM.; Weiss SW. Paraganglioma. In: Enzinger FM, Weiss SW, editors. Soft tissue tumors. 2nd ed. St. Louis: Mosby;1988. p. 836-860.

8. DeLellis RA, Lloyd RV, Heitz PU, Eng C. Pathology and genetics of tumours of endocrine organs. Lyon, France: IARC Press;2004. p. 320. 
9. Waguespack SG, Rich T, Grubbs E, Ying AK, Perrier ND, Ayala-Ramirez M, Jimenez C. A current review of the etiology, diagnosis, and treatment of pediatric pheochromocytoma and paraganglioma. JClin Endo crinol Metab 2010 May;95(5):164-165.

10. Neumann, HPH. Pheochromocytoma. In: Kasper DL, Fauci AS, Longo DL, Hauser SL, Jameson JL, Loscalzo J, editors. Harrison's principles of internal medicine. 18th ed. New York: McGraw-Hill;2012:2965.

11. Barontini M, Levin G, Sanso G. Characteristics of pheochromocytomain a 4- to 20-year-old population. Ann NY Acad Sci 2006 Aug;1073:30-37.
12. Beltsevich DG, Kuznetsov NS, Kazaryan AM, Lysenko MA Pheochromocytoma surgery: epidemiologic peculiarities in children. World J Surg 2004 Jun;28(6):592-96

13. Tischler AS. Pheochromocytoma and extra-adrenal paraganglioma: updates. Arch Pathol Lab Med 2008 Aug;132(8): 1272-84.

14. Linnoila RI, Keiser HR, Steinberg SM, Lack EE. Histopathology of benign versus malignant sympathoadrenal paragangliomas: clinicopathologic study of 120 cases including unusual histologic features. Hum Pathol 1990 Nov;21(11):1168-80. 